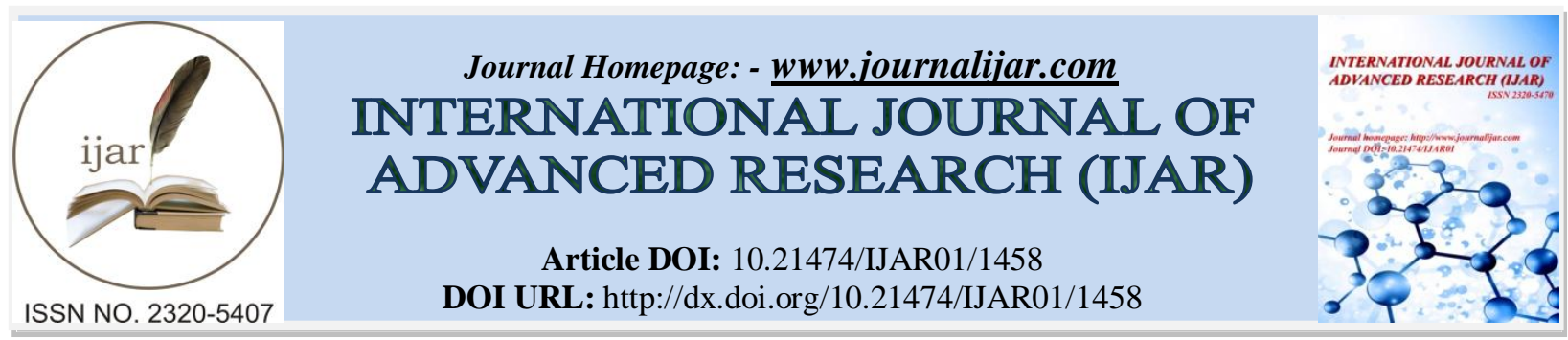

RESEARCH ARTICLE

\title{
SYNTHESIS AND CHARACTERIZATION OF SILVER NANOPARTICLES USING BLEPHARIS MADERASPATENSIS (L) HYNE EX ROTH LEAF EXTRACT AND IT'S ANTI- INFLAMMATORY ACTIVITY AGAINST HUMAN BLOOD CELLS.
}

\section{P. Kalitha Parveen* and Kandasamy Prabakar.}

Postgraduate and Research Department of Zoology, Jamal Mohamed College, Tiruchirappalli, 620020 Tamil Nadu, India.

\section{Manuscript Info}

Manuscript History

Received: 12 July 2016

Final Accepted: 16 August 2016

Published: September 2016

Key words:-

silvernanoparticles, anti-inflammatory, blepharis maderaspatensis hyne ex Roth

\section{Abstract}

In this current study green synthesis of silver nanoparticles using aqueous leaf extract of blepharis maderaspatensis and its anti inflammatory activities are evaluated. The anticipation of hypo tonicity induced HRBC membrane lysis was taken as an appraise of the anti - inflammatory activity. Results revealed that synthesized silver nanoparticles from the leaf extract of blepharis maderaspatensis hyne Ex.roth showed strong absorption maximum at $400 \mathrm{~nm}$ corresponding to the surface plasma resonance. Green synthesis of silver nanoparticles was characterized by UV-Visible spectroscopy, SEM, FTIR, XRD and Zeta potential. The size of the nanoparticles was found to be $>100 \mathrm{~nm}$ by using XRD and SEM analysis. It is a well documented fact that the silver nanoparticles synthesized from blepharis maderaspatensis hyne ex Roth leaf extract showed effective anti- inflammatory activity against human blood cells. Therefore these herbal extracts could be used in future as alternative therapeutic agents for the treatment of human diseases.

Copy Right, IJAR, 2016,. All rights reserved.

\section{Introduction:-}

The term nanoparticles are used to illustrate a particle with size in range of 1-100nm. They act as the fundamental building block of nanotechnology. Being a platform nanotechnology cures lot of human disease. Inflammation is a normal protective response to tissue injury caused by microbial agents. The symptoms of inflammation are characterized by pain, heat, redness, swelling and loss of function. It can be classified into two major types either acute or chronic, based on the duration of the inflammatory reaction. Various disorders are produced during lysosomal enzyme release. The enzyme and its cellular activity are said to be related with acute or chronic inflammation. HRBC or erythrocyte membrane is analogous to the lysosomal membrane. One of the best treatments of inflammatory disease is Phytomedicine. The most commonly used drug for inflammatory disorders are nonsteroidal anti- inflammatory drugs which have unpleasant effects especially gastric irritation leading to formation of gastric ulcers. Purified natural compounds from plants have aided in the synthesis of new generation antiinflammatory drugs with higher therapeutic value and lower toxicity. Although there are lot of nanoparticles available, silver always plays an effective role because of its adverse and potential biological properties. From ancient times silver is used to treat inflammation and wounds. Silver nanoparticles are synthesized using various methods like physical, chemical and biological methods. The use of biological systems is widely explored because

Corresponding Author:-P. Kalitha Parveen

Address:- Postgraduate and Research Department of Zoology, Jamal Mohamed College,

Tiruchirappalli, 620020 Tamil Nadu, India. 
of its economical and eco- friendly nature. The phytoconstituents acts as capping agents which confer the silver nanoparticles with pharmacological activities.

Blepharis maderaspatensis belongs to the family Acanthaceae. It is afro- Asiatic genus comprising 129 species which occur in arid and semi -arid habitats. Its common name is creeping blepharis and seen commonly on slopes, among rocks, poor gravelly soil on the hills up to $1400 \mathrm{~nm}$. A diffuse, prostrate or procumbent, slender herb, 30-90 $\mathrm{cm}$ high. Leaves are economically important and are good medicine for throat troubles and asthma. Blepharis maderaspatensis is reported to contain alkaloids, phenols, flavonoids, steroids, saponins and tannins. It is used to study embryological studies, anthropogenic, brain disorder, bone fracture and Parkinson's disease and it is also used as anti- bacterial, anti- larvicidal, anti- inflammatory, anti-nociceptive and anti- cancer. This review contains the phyto chemical constituent, pharmacological activity and traditional uses of various parts of plant. Blepharis maderaspatensis seeds are of economically important and good source for ulcer. They are considered as attenuate, resolvent, diuretic, and expectorant and deobstruent. They are dried and the steroid gomisin D is used to treat Parkinson's disease. Leaves are expectorant and used to treat the disorders such as bone fracture, boils, diarrohea and lactation. Paste of leaves is mixed with lime juice and applied on cuts. Leaf juice is used in throat troubles and asthma. Stem an astringent for the bowels, aphrodisiac used in leucoderma, mental de arrangements and is applied to wounds and ulcers. This scrambling perennial herb is used traditionally for treatment of snakebites, wounds, oedema and gout. It is also used for treatment of a number of ailments like dysuria, headache, and diseases of nervous system, diuretic and aphrodisiac.

\section{Materials and methods:-}

Silver nanoparticles synthesis:-

The leaves of blepharis maderaspatensis hyne ex Roth were collected from the hills area of megamalai theni DT Tamil nadu India. The materials were shade dried for $10-15$ days with ambient temperature. They were crushed into fine powder using an electronic blender. The fine powder of the leaf was extracted at $47^{\circ} \mathrm{C}$ by using Soxhlet apparatus. The extract were dried and stored for further studies. $1 \mathrm{ml}$ of the extract was added to $100 \mathrm{mal}$ of $1 \mathrm{mM}$ silver nitrate solution. The mixture was stirred using electric blender and centrifuged at $3000 \mathrm{rpm}$ for $10 \mathrm{~min}$ and was used for further studies like characterization and analysis.

\section{Characterization of silver nanoparticles:-}

UV- Vis studies:-

The reduction of silver nitrate into silver ions was estimated by measuring the UV-Vis spectrum. The absorbance was recorded at a resolution of $1 \mathrm{~nm}$ at $300-600 \mathrm{~nm}$ using UV-Vis spectrophotometer.

\section{SEM analysis:-}

The structure and the size of the nano particles were analyzed using scanning electron microscope. The sample was prepared as a $1 \mu \mathrm{g}$ thin film and coated in a copper grid by dropping method and the excess amount of solution in the grid is wiped out using blotting paper and it is allowed to dry under a Mercury lamp for five minute to get fine results. The images of nanoparticles were studied using SEM (JPEG, model JFC -1600).

\section{FTIR analysis:-}

Perkin-Elmer spectrometer FTIR Spectrum in the range 4000-400 $\mathrm{cm}^{-1}$ at a resolution of $4 \mathrm{~cm}^{-1}$ was used for the analysis. The sample was mixed with $\mathrm{KBr}$ crystals. Thin sample disc was prepared by pressing with the disc preparing machine and placed in Fourier Transform Infrared [FTIR] for the analysis of the nanoparticles as well as for the leaf extract.

\section{XRD analysis:-}

The dried pellet was purified and the silver nanoparticles were further analyzed with X-ray diffractrometer. The data obtained for silver as matched with the joint committee on powder diffraction standards JCPDS. The grain size of the silver nanoparticles formed in the process was estimated from the debye-scherrer equation. The quality of the dried mixture was analyzed by XRD technique (PAN analytical BV, Netherlands) operated at a voltage of 40kv, and a current of $30 \mathrm{~mA}$, with $\mathrm{CuKa}$ radiation in an h-2-h configuration.

\section{Zeta potential analysis:-}

Zeta potential of Ag NPs was measured according to Tantra, et.al with the help of Zetasizer Nano ZS (Malvern) and a titrator MPT-2. Before the measurement, aqueous suspension of silver nanoparticles was filtered through a 0.45 
$\mu \mathrm{m}$ PTFE membrane. The zeta potential was calculated by the help of the software.

\section{In vitro anti - inflammatory activity}

\section{The human red blood cell (HRBC) membrane:- Stabilization method:-}

The human red blood cell (HRBC) membrane stabilization method was used for this study. This assay was performed to find the anti-inflammatory activity of both the samples. $3 \mathrm{~mL}$ of blood was collected from the vein of healthy human volunteer who was not taken any NSAIDS for two weeks prior to the experiment, it was aspirated aseptically into centrifuge tube and equal volume of alsever's solution ( $2 \%$ dextrose, $0.8 \%$ sodium citrate, $0.5 \%$ citric acid and $0.42 \% \mathrm{NaCl}$ ) was added and was centrifuged at 1000rpm for 10mins. After centrifugation, the supernatant was removed; the pellet was washed with iso saline $(0.85 \% \mathrm{NaCl})$ solution until we obtained the clear supernatant. Then finally the pellet was stored with equal amount of iso saline and was further used. The assay mixture was prepared by taking $0.5 \mathrm{ml}$ of test sample, $1 \mathrm{ml}$ of $0.2 \mathrm{M}$ of phosphate buffer, $2 \mathrm{ml}$ of hypo saline, and $0.5 \mathrm{ml}$ of blood suspension. Control was prepared by taking $0.5 \mathrm{ml}$ of distilled water, $1 \mathrm{ml}$ of $0.2 \mathrm{M}$ of phosphate buffer, $2 \mathrm{ml}$ of hypo saline, and $0.5 \mathrm{ml}$ of blood suspension. This assay mixture was incubated at $37^{\circ} \mathrm{C}$ for $30 \mathrm{mins}$. After incubation the assay mixture was centrifuged at $1000 \mathrm{rpm}$ for $5 \mathrm{mins}$ and the hemoglobin content in the supernatant was measured by taking the OD value at $560 \mathrm{~nm}$ using UV spectrophotometer. Blepharis extract was considered as standard. The experiments were performed thrice and the mean values were taken for study.

\section{Results:-}

\section{UV-VIS spectro analysis:-}

UV-VIS spectrophotometer measurements were performed after the extraction of silver nanoparticles. The aqueous and silvernanoparticles are the two samples undergone the measurements. The silver nanoparticles in the solution could be correlated with the respective UV-VIS spectrum. It exhibited a strong absorption between 300nm and $600 \mathrm{~nm}$.

\section{SEM analysis:-}

SEM indicates the presence of nanoparticles. It revealed that the nanoparticles of silver are spherical in shape and also cubic too. The average size of the nanoparticles was studied, from the image it can be seen that the spherical morphology of silver nanoparticles is randomly distributed with average diameter $>100 \mathrm{~nm}$. The morphology of the silver nanoparticles was determined by using scanning electron microscopy.

\section{XRD analysis:-}

Silver nanoparticles showed the diffraction peaks which indicated the metallic face centered cubic silver phase. In addition AgNps had a similar diffraction profile (Ag XRD ref No. 01-087-0719), and XRD peaks at $2 \theta$ of $38.18^{\circ}$, $44.32^{\circ}, 57.52^{\circ}, 64.50^{\circ}$ and $77.05^{\circ}$ could be attributed to the $111,200,103,220$ and 311 crystallographic planes of the face-centered cubic silver crystals, respectively. The XRD pattern thus clearly illustrated that the AgNps formed in this study is crystalline in nature. The results are corresponds to the Braggs reflection. The yellowish brown colour formation of the silvernanoparticles from the leaf extract may due to surface plasmon excitation. The sharp bands of Braggs peaks may be due to the stable capacity of biosynthesized silvernanoparticles.

\section{FTIR analysis:-}

The FTIR spectrum of silvernanoparticles is shown in the table. The band at $3947 \mathrm{~cm}-1$ is assigned as O-H stretching of H-bonded alcohols and phenols. The band at 3,851cm-1 is $\mathrm{O}-\mathrm{H}$ stretching of carboxylic acids. The band at $3,712 \mathrm{~cm}-1$ corresponds to $\mathrm{N}-\mathrm{H}$ bonding of primary amines.1,652 $-1384 \mathrm{~cm}-1$ are corresponding to $\mathrm{C}-\mathrm{C}$ stretching alcohols, carboxylic acids, esters and ethers. The FTIR analysis revealed the presence of functional groups of alcohols, carboxylic acids, esters and ethers which are the binding metals to form silvernanoparticles and prevents its agglomeration.

\section{Zeta potential:-}

Zeta potential of Ag NPs was measured according to Tantra, et.al with the help of Zetasizer Nano ZS (Malvern) and a titrator MPT-2. Before the measurement, aqueous suspension of silver nanoparticles was filtered through a 0.45 $\mu \mathrm{m}$ PTFE membrane. The zeta potential was calculated by the help of the software. Stability of AgNPs is determined by zeta potential measurement. Zeta potential value $\pm 30 \mathrm{mv}$ is considered as stable nano suspension. 


\section{Anti - inflammatory activity}

The aqueous extract of the leaves of blepharis maderaspatensis hyne ex roth was studied for in vitro antiinflammatory activity by HRBC membrane stabilization method. Among all the extracts showed significant antiinflammatory activity in a concentration dependent manner. The medical significance of blepharis maderaspatensis hyne ex Roth has a good anti-inflammatory activity. As the concentration of sample increases the percentage of inhibition also increases. All the results were compared with standard. The extracts and the extracts containing silver nanoparticles revealed membrane stabilization effect by lyses of erythrocyte membrane.

The erythrocyte membrane and its stabilization reveal that the extract may also well stabilize lysosomal membrane. Stabilization of lysosomal membrane activated bactericidal enzymes and proteases to limit the inflammatory response.

Fig 1:- UV-VIS spectral analysis.

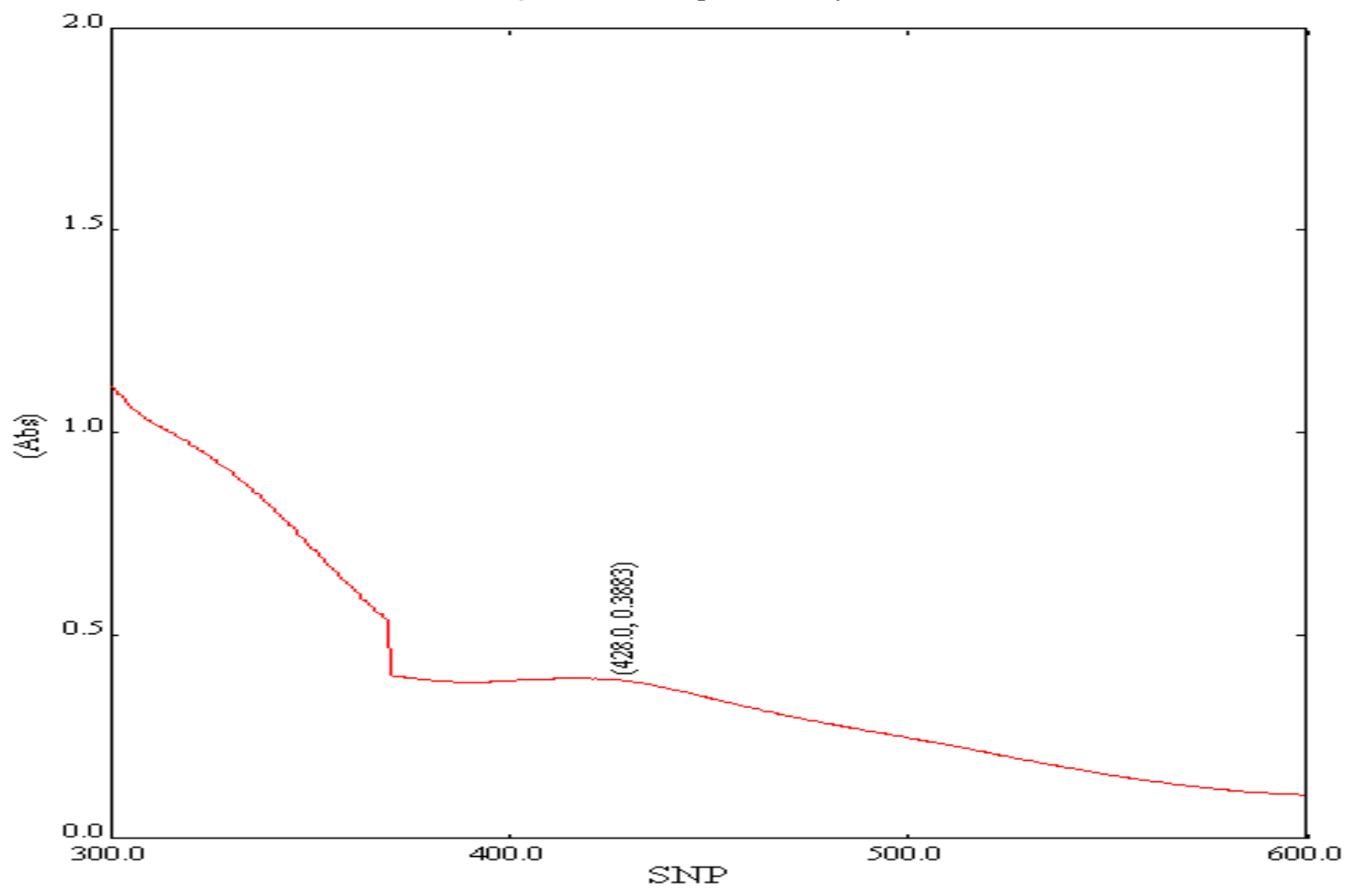


Fig 2:- SEM analysis.

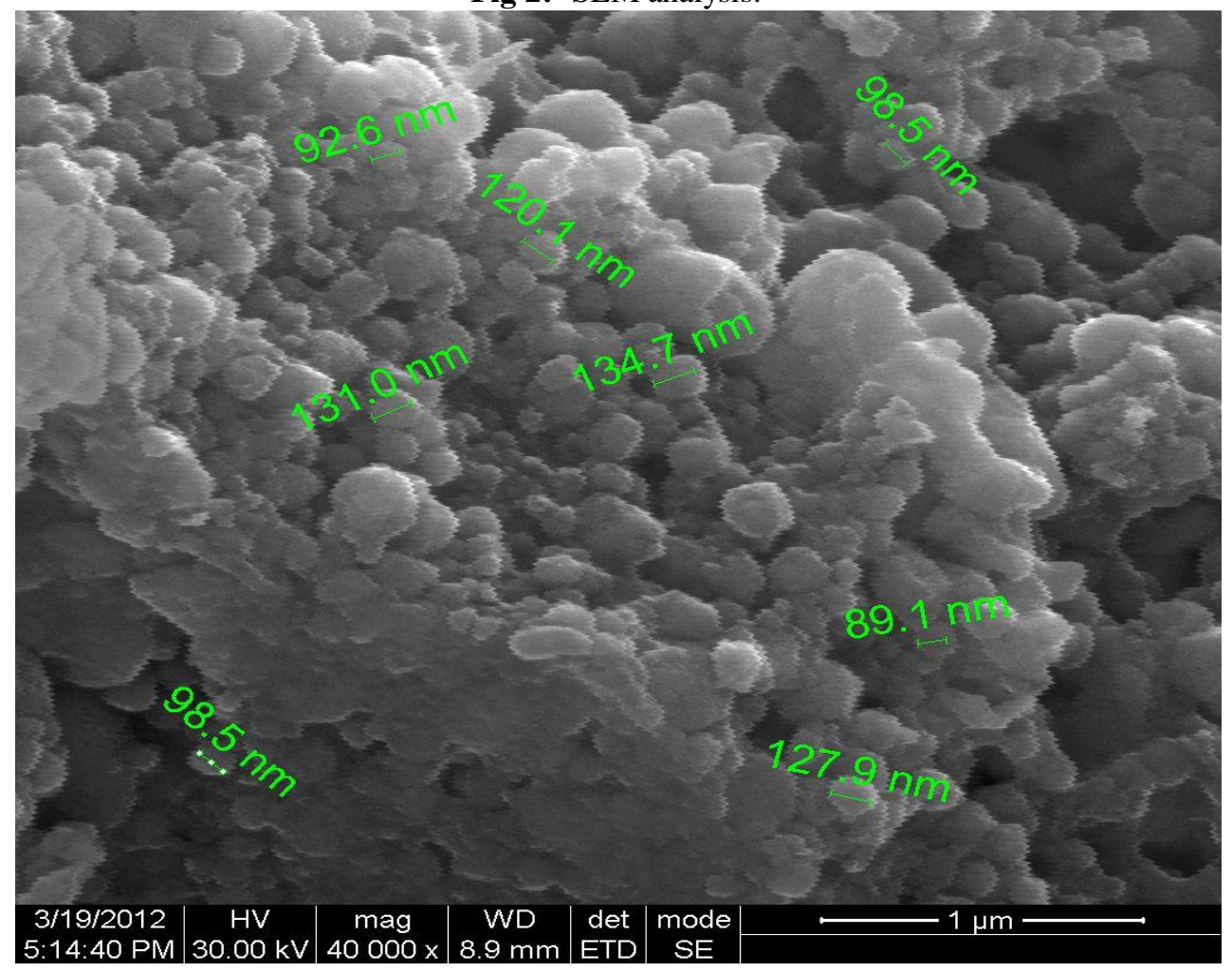

Fig 3:- XRD analysis of biosynthesized silvernanoparticles from blepharis maderaspatensis hyne Ex.roth Counts

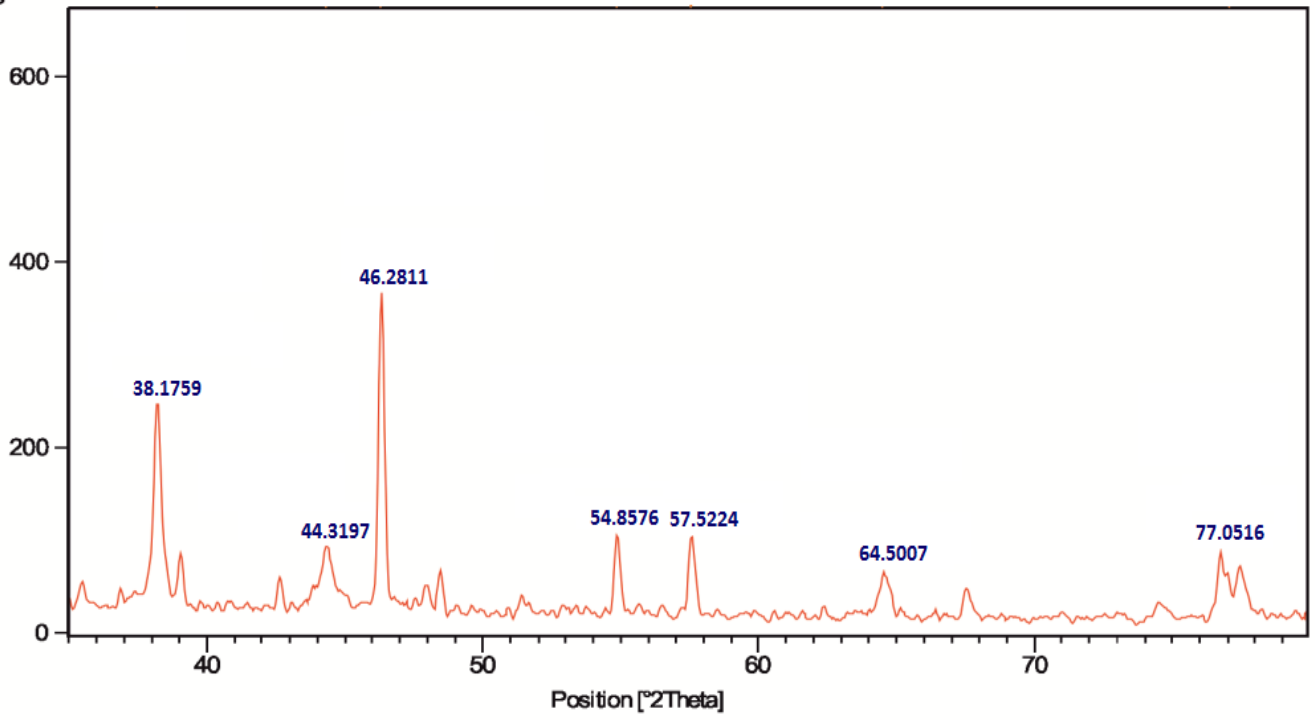


Fig 4:- FTIR analysis of biosynthesized silvernanoparticles from blepharis maderaspatensis hyne Ex.roth

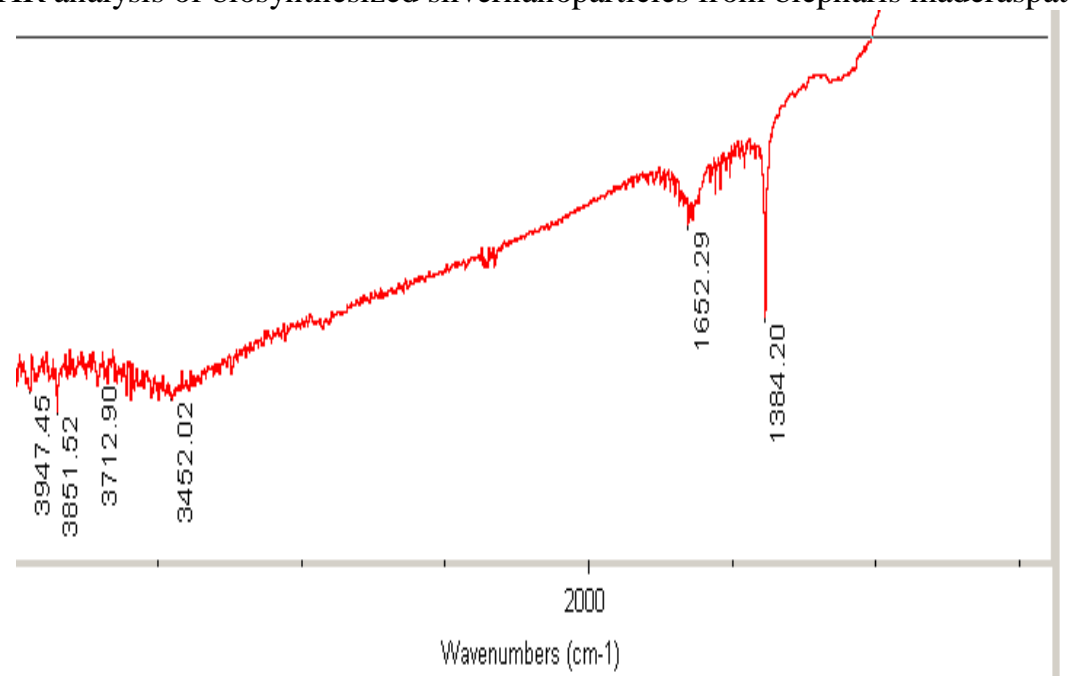

Fig 5:- zeta potential analysis of biosynthesized silver nanoparticles from blepharis maderaspatensis leaf extract.

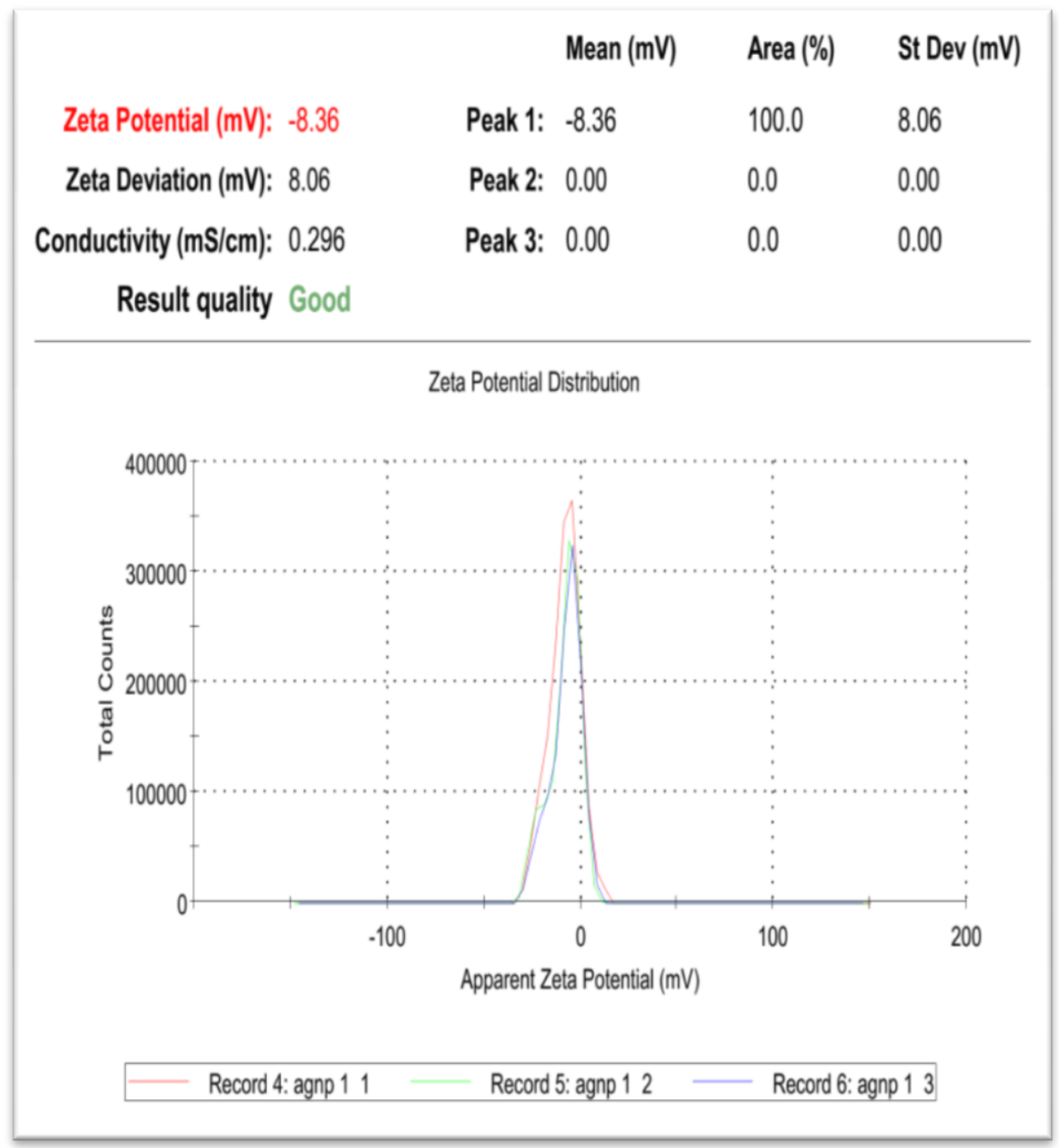




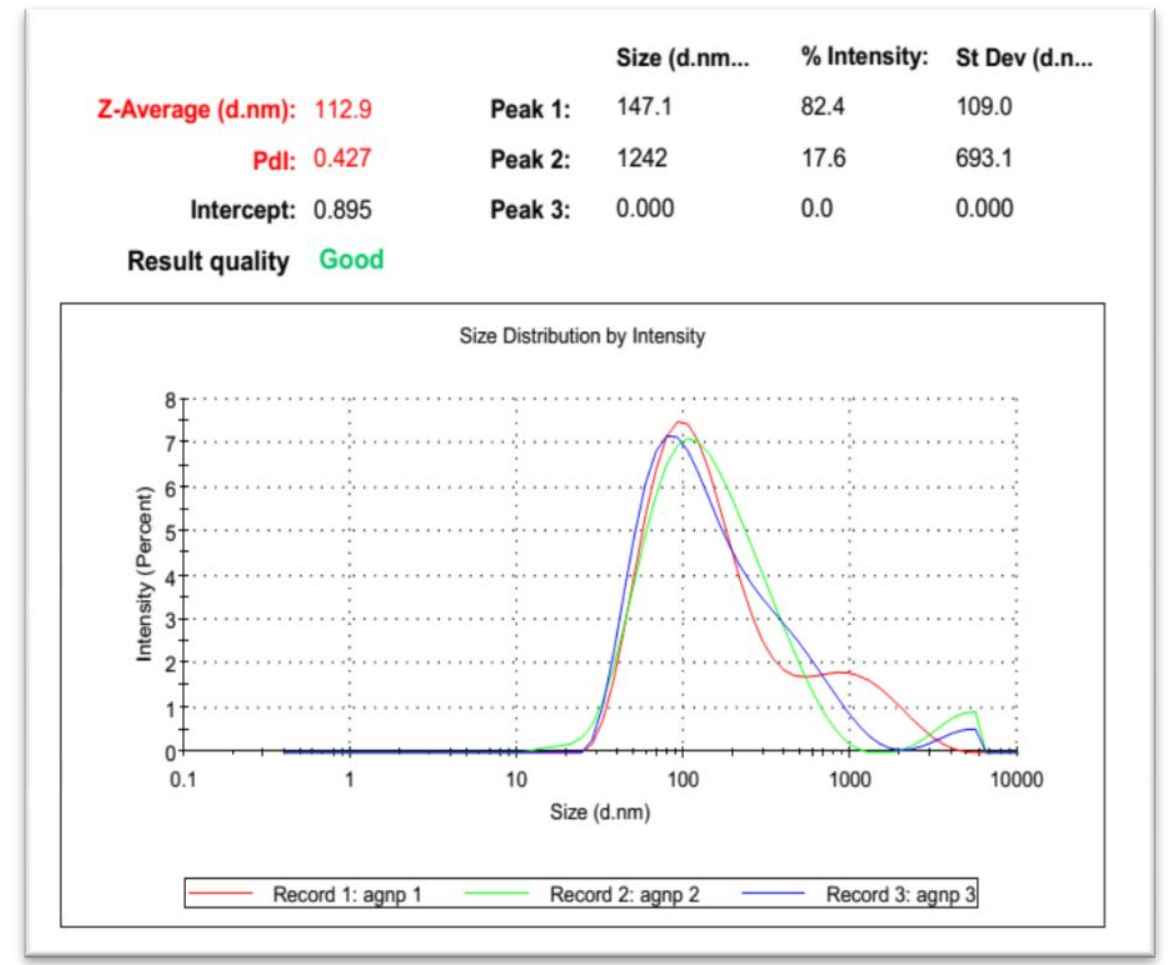

Fig 6:- blepharis leaf.

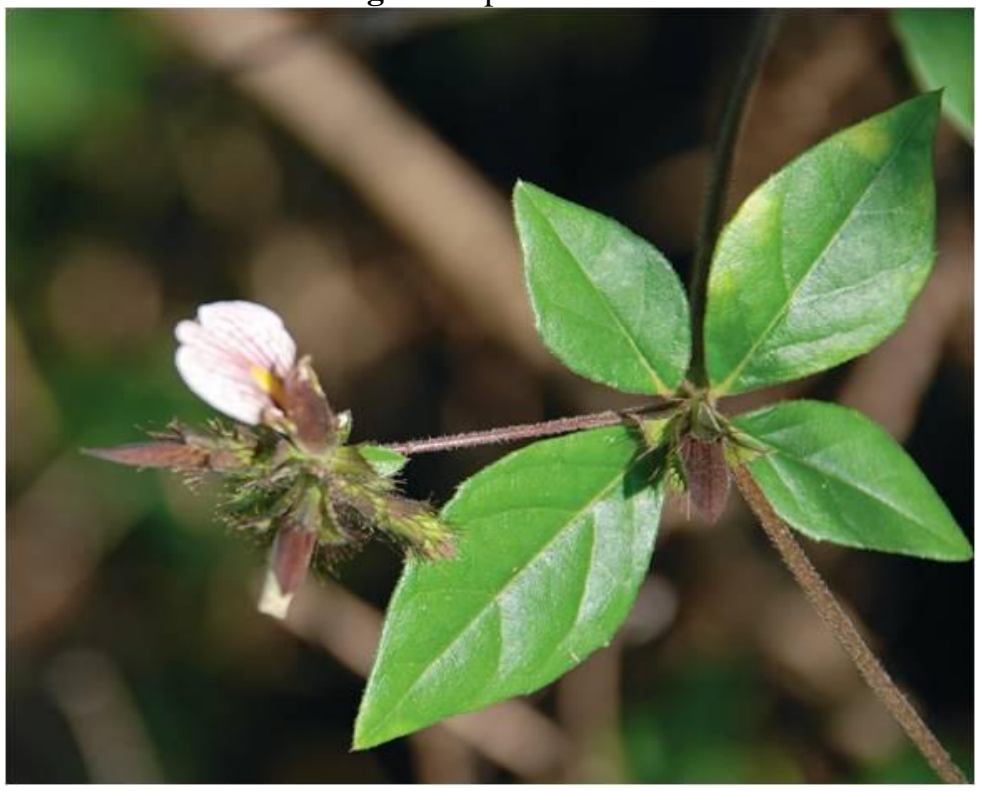

Aqueous extract:

Control - 0.312 (O.D)

\begin{tabular}{|l|l|l|}
\hline Sample & OD value at 560nm & Mean value \pm SD \\
\hline T1 & 0.732 & \multirow{2}{*}{$0.736 \pm 0.008$} \\
\hline T2 & 0.731 & \\
\hline
\end{tabular}


Silver nano particles synthesized using the aqueous extract of plant sample as the reducing agent:

\begin{tabular}{|l|l|l|}
\hline Sample & OD value at 560nm & Mean value \pm SD \\
\hline T1 & 0.295 & \multirow{3}{*}{$0.297 \pm 0.007$} \\
\hline T2 & 0.286 & \\
\hline T3 & 0.301 & \\
\hline
\end{tabular}

\section{Discussion:-}

The significance of nano-herbal-technology improved anti-inflammatory activity properties is an area of current research in biological arenas. In our study, we reported the non toxic, environmental friendly benevolent approach for the synthesis of silver nanoparticles using the aqueous extract of blepharis maderaspatensis hyne ex roth plant with potent anti-inflammatory activity. Inflammation is a normal protective response to tissue injury caused by physical, chemical or biological agents. This significant anti-inflammatory effect may be due to the inhibition of any inflammatory mediators by the bio active substances present in the extract. The present result indicates the efficacy of blepharis maderaspatensis hyne ex. Roth as an effective therapeutic agent in the treatment of acute inflammations. The result of present study authentifies the folk lore information on the anti-inflammatory property of the leaf extract of blepharis maderaspatensis hyne ex Roth. Further and detailed studies are the possible mechanism of its anti inflammatory property.

\section{References:-}

1. Wijayasiriwardena, C., Chauhan, M.G., Sharma, P.P., Lahiri, S.K., Shah, M.B., 2009. Anti-inflammatory activity of Delonix elata (L.) gambles. Journal of natural remedies.vol. 9(2), $209-215$.

2. Muruganathan G, and Mohan S. Anti-inflammatory and Anti-Arthritic activities of Delonix elata bark extracts. Int J Res Ayu Pharm.2011; 2(6):1819-1821.

3. M. G. Sethuraman and N. Sulochana, "The anti-inflammatory activity of Delonix elata," Current Science, vol. 55, pp. 343-344, 1986.

4. Festus BC, Okoye, Patience O, Osadebe. Studies on the mechanisms of anti-inflammatory activity of the extracts and fractions of Alchornea floribunda leaves. Asian Pac J Trop Med 2009; 2(3): 7-14.

5. Ejebe DE, Siminialayi IM, Emudainowho JOT, Ofesi U, Morka L. Analgesic and anti-inflammatory activities of the ethanol extract of the leaves of Helianthus Annus in Wistar rats. Asian Pac J Trop Med 2010; 3(5): 341347.

6. Nia R, Paper DH, Essien EE, Oladimeji OH, Iyadi KC, et al. (2003) Investiagation into in-vitro radical scavenging and in-vivo anti-inflammatory potential of Tridax procumbens. Niger J Physiol Sci 18: 39-43

7. Parashar V, Parashar R, Sharma B, Pandey AC (2009) Parthenium leaf extract mediated synthesis of silver nanoparticles: a novel approach towards weed utilization. Dig J Nanomater Biostruct 4: 45-50

8. Georgewill OA, Georgewill UO. Evaluation of the anti-inflammatory activity of extract of Vernonia Amygdalina. Asian Pac J Trop Med 2010; 3(2): 150-151.

9. Gandhidasan R, Thamaraichelvan A, Baburaj. Anti-inflammatory action of Lanea coromondelica by HRBC membrane stabilization. Fitotherapia 1991; 62: 82-83. 